Fixed Point Theory, 18(2017), No. 1, 85-106

http://www.math.ubbcluj.ro/ nodeacj/sfptcj.html

\title{
TOPOLOGICAL DEGREE AND ATYPICAL BIFURCATION RESULTS FOR A CLASS OF MULTIVALUED PERTURBATIONS OF FREDHOLM MAPS IN BANACH SPACES
}

\author{
PIERLUIGI BENEVIERI* AND PIETRO ZECCA** \\ *Dipartimento di Matematica e Informatica, Università degli Studi di Firenze \\ Via S. Marta 3, I-50139 Firenze, Italy \\ and Instituto de Matemática e Estatística, Universidade de São Paulo \\ Rua do Matão 1010, São Paulo - SP - Brasil - CEP 05508-090 \\ E-mail: pierluigi.benevieri@unifi.it, pluigi@ime.usp.br \\ ** Dipartimento di Matematica e Informatica, Università degli Studi di Firenze \\ Via S. Marta 3, I-50139 Firenze, Italy \\ E-mail: pietro.zecca@unifi.it
}

Abstract. We obtain a global (atypical) bifurcation result for a semilinear inclusion problem in Banach spaces. The approach is topological, making use of a topological degree introduced by the second author for locally compact multivalued perturbations of nonlinerar Fredholm maps. We also study some specific aspects of the construction of this concept of degree.

Key Words and Phrases: Topological degree, nonlinear Fredholm maps, Banach spaces, multivaued compact maps, global bifurcation.

2010 Mathematics Subject Classification: 34C23, 34A60, 47H11, 47A53, $47 \mathrm{H} 14$.

\section{REFERENCES}

[1] P. Benevieri, M. Furi, A simple notion of orientability for Fredholm maps of index zero between Banach manifolds and degree theory, Ann. Sci. Math. Québec, 22(1998), 131-148.

[2] P. Benevieri, M. Furi, On the concept of orientability for Fredholm maps between real Banach manifolds, Topol. Meth. Nonlinear Anal., 16(2000), 279-306.

[3] P. Benevieri, M. Furi, M. Martelli, M.P. Pera, Atypical bifurcation without compactness, Z. Anal. Anwendungen, 24(2005), no. 1, 137-147.

[4] P. Benevieri, M. Furi, A degree theory for locally compact perturbations of Fredholm maps in Banach spaces, Abstr. Appl. Anal. 2006, Art. ID 64764, 20 pp.

[5] P. Benevieri, A. Calamai, M. Furi, On the degree for quasi-Fredholm maps: its uniqueness and its effective extension of the Leray-Schauder degree, Topol. Meth. Nonlin. Anal., 46(2015), no. $1,401-430$.

[6] Yu.G. Borisovich, B.D. Gelman, A.D. Myshkis, V.V. Obukhovskii, Topological methods in the theory of fixed points of multivalued mappings, (Russian), Uspekhi Mat. Nauk, 35(1980), no. 1 (211), 59-126. English translation: Russian Math. Surveys, 35(1980), 65-143.

[7] Yu.G. Borisovich, B.D. Gelman, A.D. Myshkis, V.V. Obukhovskii, Introduction to the Theory of Multivalued Maps and Differential Inclusions, Librokom, Moscow, 2011. (in Russian)

The authors have been partially sponsored by Fapesp, Grant n. 2012/22926-0. 
[8] K. Borsuk, Theory of Retracts, Monografie Mat. 44, PWN, Warszawa, 1967.

[9] K.D. Elworthy, A.J. Tromba, Differential structures and Fredholm maps on Banach manifolds, in Global Analysis (S.S. Chern and S. Smale-Eds.), Proc. Symp. Pure Math., 15(1970), 45-94.

[10] K.D. Elworthy, A.J. Tromba, Degree theory on Banach manifolds, in Nonlinear Functional Analysis (F.E. Browder-Ed.), Proc. Symp. Pure Math., Vol. 18 (Part 1), 1970, 86-94.

[11] M. Furi, M.P. Pera, Co-bifurcating branches of solutions for nonlinear eigenvalue problems in Banach spaces, Annali di Matem. Pura e Applicata, 85(1983), no. 4, 119-132.

[12] M. Furi, M.P. Pera, A continuation principle for periodic solutions of forced motion equations on manifolds and applications to bifurcation theory, Pacific J. Math., 160(1993), no. 2, 219-243.

[13] L. Górniewicz, Topological Fixed Point Theory of Multivalued Mappings, Springer, Dordrecht, 2006.

[14] L. Górniewicz, A. Granas, W. Kryszewski, On the homotopy method in the fixed point index theory of multi-valued mappings of compact absolute neighborhood retracts, J. Math. Anal. Appl., 161(1991), no. 2, 457-473.

[15] W.E. Haver, Locally contractible spaces that absolute neighborhood retracts, Proc. Amer. Math. Soc., 40(1973), no. 1, 280-284.

[16] V. Guillemin, A. Pollack, Differential Topology, Prentice Hall, Inc., Englewood Cliffs, New Jersey, 1974.

[17] D.M. Hyman, On decreasing sequences of compact absolute retracts, Fund. Math., 64(1969), 91-97.

[18] T. Kato, Perturbation Theory for Linear Operators, Grundlehren der Mathematischen Wissenschaften, 132, Springer-Verlag, Berlin, 1980.

[19] M. Kamenskii, V. Obukhovskii, P. Zecca, Condensing Multivalued Maps and Semilinear Differential Inclusions in Banach Spaces, de Gruyter Series in Nonlinear Anal. Appl., 7, Walter de Gruyter \& Co., Berlin, 2001.

[20] N. Lloyd, Degree Theory, Cambridge University Press, 1978.

[21] M. Martelli, Large Oscillations of Forced Nonlinear Differential Equations, Amer. Math. Soc. Contemporary Mathematics, 21(1983), 151-159.

[22] A.D. Myshkis, Generalizations of the theorem on a stationary point of a dynamical system inside a closed trajectory, Math. Sb., 34(1954), 525-540. (in Russian)

[23] L. Nirenberg, Topics in Nonlinear Functional Analysis, Courant Institute of Mathematical Sciences, New York, 1974.

[24] V. Obukhovskii, P. Zecca, V. Zvyagin, An oriented coincidence index for nonlinear Fredholm inclusions with nonconvex valued perturbations, Abstr. Appl. Anal. 2006, Art. ID 51794, 21 pp.

[25] V. Obukhovskii, P. Zecca, N. Van Loi, S. Kornev, Method of Guiding Functions in Problems of Nonlinear Analysis, Springer-Verlag, Berlin, Heidelberg, 2013.

[26] G. Prodi, A. Ambrosetti, Analisi non lineare, Quad. 1, Scuola Norm. Sup. Pisa, 1973.

[27] M. Väth, Topological Analysis - From the basics to the triple degree for nonlinear Fredholm inclusions, De Gruyter Series in Nonlinear Anal. Appl., 16, Walter de Gruyter \& Co., Berlin, 2012.

[28] V.G. Zvyagin, N.M. Ratiner, Oriented degree of Fredholm maps: finite-dimensional reduction method, J. Math. Sciences, 204(2015), no. 5, 543-714.

Received: September 20, 2015; Accepted: October 8, 2015. 